\title{
Transcriptomic profiles reveal the genome-wide responses of the harmful dinoflagellate Cochlodinium polykrikoides when exposed to the algicide copper sulfate
}

\author{
Ruoyu Guo ${ }^{1}$, Hui Wang ${ }^{1}$, Young Sang Suh ${ }^{2}$ and Jang-Seu Ki ${ }^{*}$
}

\begin{abstract}
Background: Harmful algal blooms (HABs) caused by the dinoflagellate Cochlodinium polykrikoides lead to severe environmental impacts in oceans worldwide followed by huge economic losses. Algicide agent copper sulfate $\left(\mathrm{CuSO}_{4}\right)$ is regard as an economical and effective agent for HABs mitigation; its biochemical and physiological effects were revealed in C. polykrikoides. However, molecular mechanisms of $\mathrm{CuSO}_{4}$ effect on the C. polykrikoides, even other $\mathrm{HAB}$ species, have not been investigated. The present study investigated the transcriptional response of C. polykrikoides against $\mathrm{CuSO}_{4}$ treatments, with the aim of providing certain molecular mechanism of $\mathrm{CuSO}_{4}$ effect on the C. polykrikoides blooms.

Results: RNA-seq generated 173 million reads, which were further assembled to 191,212 contigs. 43.3\%, $33.9 \%$, and $15.6 \%$ of contigs were annotated with NCBI NR, GO, and KEGG database, respectively. Transcriptomic analysis revealed $20.6 \%$ differential expressed contigs, which grouped into 8 clusters according to $K$-means clustering analysis, responding to $\mathrm{CuSO}_{4} ; 848$ contigs were up-regulated and 746 contigs were down-regulated more than 2 -fold changes from $12 \mathrm{~h}$ to $48 \mathrm{~h}$ exposure. KEGG pathway analysis of eukaryotic homologous genes revealed the differentially expressed genes (DEGs) were involved in diverse pathway; amongst, the genes involved in the translation, spliceosome, and/or signal transduction genes were highly regulated. Most of photosystem related genes were down-regulated and most of mitochondria related genes were up-regulated. In addition, the genes involved in the copper ion binding or transporting and antioxidant systems were identified. Measurement of chlorophyll fluorescence showed that photosynthesis was significantly inhibited by $\mathrm{CuSO}_{4}$ exposure.

Conclusions: This study reported the first transcriptome of the C. polykrikoides. The widely differential expressed photosystem genes suggested photosynthetic machinery were severely affected, and may further contribute to the cell death. Furthermore, gene translation and transcription processes may be disrupted, inhibiting cell growth and proliferation, and possibly accelerating cell death. However, antioxidant systems resistant to $\mathrm{CuSO}_{4}$ caused stress; mitochondrion may compensate for photosynthesis efficiency decreasing caused energy deficiency. In addition, various signal transduction pathways may be involved in the $\mathrm{CuSO}_{4}$ induced regulation network in the $\mathrm{C}$. polykrikoides. These data provide the potential transcriptomic mechanism to explain the algicide $\mathrm{CuSO}_{4}$ effect on the harmful dinoflagellate C. polykrikoides.
\end{abstract}

Keywords: Cochlodinium polykrikoides, Algicide $\mathrm{CuSO}_{4}$, Trancriptomic response, Differentially expressed genes

\footnotetext{
*Correspondence: kijs@smu.ac.kr

'Department of Life Science, College of Natural Sciences, Sangmyung

University, Seoul 110-743, Korea

Full list of author information is available at the end of the article
} 


\section{Background}

Dinoflagellates are a large group of freshwater and marine microalgae; about half of them are photosynthetic, and thus they play a crucial role in aquatic ecosystems. To date, approximately 4500 dinoflagellate species have been described, including more than 2500 extinct species from the fossil record and approximately 2000 living species [1]. Some species are responsible for harmful algal blooms (HABs, sometimes referred to as red-tide), which can severely affect aquaculture and marine environments worldwide. Hence, much effort has been directed at trying to solve problems associated with HABs, including the causes of occurrence, identification of the organisms responsible, bloom dynamics, toxin production and associated genetics, environmental monitoring, management [2-4]. Some dinoflagellates (e.g., Alexandrium tarmarense, Gymnodinium breve, and Prorocentrum minimum) can produce toxins that affect fish, shellfish, mammals, seabirds, and other consumers by persisting in the food chain. In addition, large numbers of dinoflagellate cells clog gills and/or deplete oxygen levels in the water column, sometimes leading to massive morality of marine animals $[5,6]$. To reduce these adverse effects, people have employed biological, chemical and physical approaches to control, prevent, and/or mitigate HABs [7, 8]. Amongst these, algicides that affect algae growth such as yellow loess, copper sulfate $\left(\mathrm{CuSO}_{4}\right)$, hydrogen peroxide $\left(\mathrm{H}_{2} \mathrm{O}_{2}\right)$, and oxidizing chlorine $\left(\mathrm{Cl}_{2}\right)$ are regarded as effective ways to manage algal blooms, and can be applied in doses considered safe for environmental health $[7,9,10]$. To date, studies on the effects of these algicides on HAB species have mainly focused on the biocidal efficiency, by measuring cell growth, pigment content, and photosynthetic efficiency. Recently cellular and biochemical responses of functional genes, such as those involved in photosynthesis, to algicides have been assessed $[9,11,12]$.

As unicellular microeukaryotes, dinoflagellates have distinct genomic characters (e.g., permanently condensed and liquid-crystalline chromosomes, very large nuclear genome sizes, low amounts of histones, $70 \%$ replacement of thymine with 5-hydroxymethyluracil, etc.). These properties make dinoflagellates an interesting model for genomic research [13]. In addition, some dinoflagellates lack typical eukaryotic transcriptional elements (e.g., TATA boxes) in the upstream regions of coding genes [14]. Hence, they may have specific regulatory mechanisms of gene expression (e.g., spliced leader transsplicing, post-transcriptional regulation, etc.). Furthermore, dinoflagellate spliced-leader (dinoSL) trans-splicing is known to be a common transcription mechanism in nuclear genomes [15]. However, recent studies have demonstrated that Symbiodinium minutum differs from other dinoflagellates in that not all its nuclear genes are dinoSL trans-splicing $[15,16]$. Moreover, Brunelle and Van Dolah [17] found that cell cycle-related genes (e.g., those responsible for producing cell nuclear antigens, ribonucleotide reductase, and replication factor $\mathrm{C}$ ) were not altered at transcriptional level but at the protein level during the cell cycle in Karenia brevis. Hence, they proposed that expression of these genes was regulated post-transcription in this dinoflagellate. To the best of our knowledge, the transcriptional responses of dinoflagellate genes vary widely in different environmental conditions [18-20]. These findings show that dinoflagellate genes regulation may be affected by environmental changes.

From a molecular perspective, the large genomes of HAB-forming dinoflagellates implies that they should have specific duplication mechanisms (e.g., a permanently present nuclear membrane, even during mitosis) to allow rapid proliferation, especially during bloom initiation. Therefore, dinoflagellate genome and transcriptional studies may help in understanding these molecular mechanisms in HAB-forming species. Recently developed molecular methods (e.g., next generation sequencing and microarrays) have been applied to investigate the genome and transcriptome characteristics of HAB-forming species $[16,18,20-23]$. In addition, the roles of gene expression and regulation in mediating the effects of nutrient availability on HAB-forming dinoflagellate growth have been studied [20, 24]. Despite these advances, few studies have examined the molecular mechanisms leading to HAB termination, particularly the genome-wide gene responses to algicides

The marine dinoflagellate Cochlodinium polykrikoides is widely distributed in tropical and temperate zones throughout the world (see review by Kudela and Gobler [25]). The species causes fish mortality by producing massive amounts of mucous and depleting dissolved oxygen [26]. The HABs formed by C. polykrikoides lead to serious economic losses and environmental impacts. They are highly toxic to organisms that feed upon them, especially fish [26, 27]. Recently, C. polykrikoides has spread to many oceanic regions, including Europe, India, the Middle East, and North America [25]. Many studies on the species have been carried out in the last three decades, including environmental surveys, studies aimed at mitigation of harmful effects, those documenting global expansion, etc. However, studies on the effects of algicides at the cellular and genome level in C. polykrikoides, or other harmful dinoflagellates, are lacking. Such studies are necessary to understand the molecular mechanisms underlying bloom initiation, expansion, and termination.

In recent studies, we examined the physiological responses of $C$. polykrikoides to a common biocide (hereafter referred to as algicide), $\mathrm{CuSO}_{4}$, and found significant decreases of cell number and the pigment content as well as chlorophyll autofluorescence intensity [10]. 
These results indicate that the algicide had a considerable effect on C. polykrikoides at the cellular level, even greater than that of other chemicals such as yellow loess (unpublished data). In this study, we tested the effects of the algicide copper sulfate on the transcriptional responses of $C$. polykrikoides to understand its effects at the molecular level. First, we obtained large-scale cDNA sequences for C. polykrikoides, investigated the transcripts of cells exposed to copper sulfate, and then characterized these with bioinformatics tools, including the NCBI non-redundant protein (NR) database, the gene ontology (GO) database, and the Kyoto Encyclopedia of Genes and Genomes (KEGG) database. In addition, we investigated the transcriptome response to determine how copper sulfate affects C. polykrikoides at the genomic level and what kinds of gene regulation mechanisms are involved its defensive response.

\section{Methods}

\section{Culture and algicide treatment}

A strain (CP-01) of C. polykrikoides was obtained from the National Fisheries Research and Development Institute (NFRDI) of Korea, and cultured in $\mathrm{f} / 2$ medium at $20{ }^{\circ} \mathrm{C}$ under a 12:12-h light-dark cycle with a photon flux density of about $65 \mu \mathrm{mol}$ photons $\mathrm{m}^{-2} \mathrm{~s}^{-1}$.

At the exponential growth phase, cells of C. polykrikoides were exposed to the algicide copper sulfate $\left(\mathrm{CuSO}_{4}\right.$, Cat. No. C1297, Sigma, MO) with final concentration of $1 \mathrm{mg} \mathrm{L}{ }^{-1}$. The $\mathrm{CuSO}_{4}$ concentration used in this study was selected according to the median effective concentration value $\left(\mathrm{EC}_{50}\right.$ value) tested by [28], which was 10 times lower than reported $\mathrm{EC}_{50}$ value. The exposed cultures were harvested at $12 \mathrm{~h}, 24 \mathrm{~h}$, and $48 \mathrm{~h}$, and the untreated cells were used as control.

\section{RNA extraction and cDNA library construction}

C. polykrikoides cultures were harvested using centrifugation at $1000 \mathrm{~g}$ for $6 \mathrm{~min}$, immediately frozen in liquid nitrogen, and stored at $-80{ }^{\circ} \mathrm{C}$ until RNA extraction. Preserved cells were physically broken by freeze-thawing in liquid nitrogen, and further homogenized with a mini-beadbeater (BioSpec Products Inc., Bartlesville, OK) with zirconium beads $(0.1 \mathrm{~mm}$ diameter). Total RNA was isolated using TRIzol (Invitrogen, Carlsbad, CA), and purified using Mini Spin Columns from RNeasy Mini Kits (Qiagen, Valencia, CA). Total RNA integrity and quality were checked using an Agilent 2100 Bioanalyzer (Aglient, Santa Clara, CA). The cDNA library for subsequent cluster generation was prepared using the reagents provided in the Illumina ${ }^{-}$TruSeq $^{\text {Tw }}$ RNA Sample Preparation Kit (RS-122-2001, Illumina Inc., San Diego, CA). Sequencing was finished by a commercial service (Macrogen Inc., Seoul, Korea) using the Illumina HiSeq 2500 (Illumina Inc., San Diego, CA).

\section{Transcriptome assembly and functional annotation}

The quality of raw reads was checked with FastQC_v0.10.0 (http://www.bioinformatics.bbsrc.ac.uk/projects/fastqc/). The raw data were cleaned and trimmed by removing adaptor and low quality reads, and then reads were assembled using Trinity software [29]. The contigs were annotated by BLASTX alignment, with $E$-value $<0.001$, against the NCBI non-redundant protein (NR) database. For pathway enrichment analysis, the contigs were assigned to the Kyoto Encyclopedia of Genes and Genomes (KEGG) database [30] using the single-directional best hit (SBH) method contained in the online tool, KEGG Automatic Annotation Server. Functional annotation of contigs by gene ontology (GO) was carried out with Blast2go software [31]. The raw read transcriptome sequences were submitted to the NCBI Sequence Read Archive database (accession number SRR1548539).

\section{Analysis of differentially expressed genes}

The gene expression levels of the contigs were calculated as fragments per kilobase of transcript per million mapped reads (FPKM). The degree of differential gene expression in $\mathrm{CuSO}_{4}$ treated samples was calculated by comparison to the control (untreated exponential growth phase samples). The $\log _{2}$ ratio $\geq 1$ (fold change $\geq$ 2) was used as the threshold to define significantly differentially expressed genes (DEGs). All the DEGs were analyzed by clustering algorithm analysis using $K$-mean clustering. The identified eukaryote DEGs were mapped to the GO and KEGG databases. In the KEGG analysis, KEGG database assignment showed that some contigs coded for the same proteins, and the KEGG pathway analysis accounted for this when calculating the number of coded proteins. Contigs that coded for the same protein were considered as single genes, and were counted as one. In addition, the DEGs were further manually characterized with GO and NR database annotation by reviewing previous studies. The assembled sequences and raw FPKM values were registered in the GEO database with an accession number GSE75463.

\section{Photosynthesis and oxidative stress measurements}

Chlorophyll fluorescence was measured using a Handy PEA (Hansatech Instruments Ltd, Norfolk, UK). The parameters $F_{\mathrm{o}}, F_{\mathrm{v}}$, and $F \mathrm{~m}$ were measured at $0 \mathrm{~h}, 12 \mathrm{~h}, 24 \mathrm{~h}$, and $48 \mathrm{~h}$ after $\mathrm{CuSO}_{4}$ exposure. The ratios $F \mathrm{v} / F \mathrm{~m}$ and $F \mathrm{v} /$ $F_{\mathrm{O}}$ were calculated; $F \mathrm{v} / F \mathrm{~m}$ is an indicator of the photosynthetic efficiency, and $F \mathrm{v} / F_{\mathrm{O}}$ is a measure of the activity of the water-splitting complex on the donor side of photosystem II, as well as the size and number of active photosynthetic reaction centers [32, 33]. In addition, the maximum yield of primary photochemistry $(\Psi E O=T R o /$ ABS), and efficiency with which a trapped exciton can move an electron into the electron transport chain further 
than $\mathrm{Q}_{\mathrm{A}^{-}}(\Psi \mathrm{O}=\mathrm{Eto} / \mathrm{Tro})$ were also calculated using a Handy PEA.

To detect reactive oxygen species (ROS), cells were stained with DHR123 (D1054; Sigma) for $1 \mathrm{~h}$. The DHR123 stock solutions were directly added into cell cultures at a final concentration of $5 \mu \mathrm{M} / \mathrm{L}$. After incubation, cellular ROS content was measured with an LS55 fluorescence spectrometer (Perkin-Elmer, Waltham, MA). Lipid peroxidation was measured according to the method described in [34]. One-way analysis of variance (ANOVA) with post hoc Dunnett's multiple comparison test using Graphpad InStat (Graphpad Software, Inc., USA) was used for comparisons between control and treated cultures. Data are represented as mean \pm SD, and $P<0.05$ was considered statistically significant.

\section{Quantitative real-time PCR for gene validation}

Some DEGs of interest were selected and validated using quantitative real-time PCR (qRT-PCR). The primers used in the qRT-PCR are listed in Additional file 1. All qRT-PCR reactions were performed with TOPreal $^{\mathrm{mm}}$ qPCR 2X PreMIX (TOP, enzynomics, Korea) in a CFX96 Real-Time PCR Detection System (Bio-Rad; Hercules, CA). The qRT-PCR conditions were as follows: $4 \mathrm{~min}$ at $50{ }^{\circ} \mathrm{C} ; 10 \mathrm{~min}$ at $95{ }^{\circ} \mathrm{C}$, followed by 40 cycles of $10 \mathrm{~s}$ at $95^{\circ} \mathrm{C}, 15 \mathrm{~s}$ at $60^{\circ} \mathrm{C}$, and $15 \mathrm{~s}$ at $72{ }^{\circ} \mathrm{C}$. All reactions were performed in triplicate, and the mean value was calculated. The specificity of the amplification was verified through the analysis of a melting curve generated by gradually heating the sample from $65{ }^{\circ} \mathrm{C}$ to $95{ }^{\circ} \mathrm{C}$. The $\alpha$-tubulin (TUA) gene, which has the most stable expression pattern known in the dinoflagellate Prorocentrum minimum [35], was used as an internal control. $C_{\mathrm{T}}$ values of qRT-PCR were obtained using CFX96 RealTime controlling software (Bio-Rad; Hercules, CA). The fold-change relative to control was calculated according to the method of Pfaffl [36]. The Spearman correlation coefficient of the gene expression results from Hiseq2500 sequencing and qRT-PCR were calculated with Origin 8 software (OriginLab Corporation, MA).

\section{Results}

\section{Transcriptome and functional gene annotations}

To profile the transcriptome of C. polykrikoides, we constructed cDNA libraries, including $\mathrm{CuSO}_{4}$ exposed samples (at $12 \mathrm{~h}, 24 \mathrm{~h}$, and $48 \mathrm{~h}$ ), and unexposed control sample. RNA sequencing generated 173 million reads from libraries, containing $26.1 \mathrm{~Gb}$ nucleotides. The raw reads were assembled with $90 \%$ similarity and 191,212 contigs with a mean length of 922 bp (Table 1). Contig length ranged from 201 to 36,127 bp (Table 1; Additional file 2). Of these contigs, 102,744 (53.7\%) were 201-600 bp in length, 38,593 (20.2 \%) were 601-bp,
Table 1 Summary of the Cochlodinium polykrikoides transcriptome

\begin{tabular}{llllll}
\hline Category Number & $\begin{array}{l}\text { N50 } \\
\text { (bp) }\end{array}$ & $\begin{array}{l}\text { Total } \\
\text { nucleotides } \\
\text { (bp) }\end{array}$ & $\begin{array}{l}\text { Maximum } \\
\text { length (bp) }\end{array}$ & $\begin{array}{l}\text { Minimum } \\
\text { length (bp) }\end{array}$ \\
\hline Read & $172,977,960$ & - & $26,119,671,960$ & - & - \\
Contigs & 191,212 & 1550 & $176,356,262$ & 36,127 & 201 \\
\hline
\end{tabular}

23,889 (12.5 \%) were 1201-1800 bp, and 25,986 (19.0 \%) were longer than $1800 \mathrm{bp}$.

In addition, individual contigs were assigned to three different protein databases: NCBI NR, Gene Ontology (GO), and Kyoto Encyclopedia of Genes and Genomes (KEGG) (Table 2). All contigs were aligned on the NCBI NR protein database by BLASTX with an $E$-value cutoff of $10^{-4}$. Of the 191,212 contigs, a total of 82,749 $(43.28 \%)$ were annotated in the NCBI NR database. Of these annotated contigs, $82.5 \%$ were assigned to eukaryotes, $16.4 \%$ were assigned to bacteria, and $1.1 \%$ were classified as 'other'. The superphylum Alveolata accounted for $16.8 \%$ of annotated contigs, including 3.6 \% Apicomplexa, 2.1 \% Ciliophora, 3.6 \% Dinophyta, and $7.6 \%$ Perkinsus. In addition, the same sequences were analyzed to the GO database, and 64,931 contigs $(33.96 \%)$ were annotated. Overall, the annotations for these contigs were similar to those obtained from NCBI NR.

In the KEGG analysis, a total of 29,983 contigs (15.6\%) were assigned to 217 KEGG pathways, excluding organismal systems and human diseases. Of these, 2297 genes were assigned to metabolic processing; 1007 to genetic information processing; 717 to environmental information processing; 666 to cellular processes (Fig. 1). The highest number of genes (586) was assigned to signal transduction, followed by carbohydrate metabolism (447 genes) and amino acid metabolism (418 genes). Furthermore, within the third level KEGG pathway (Additional file 3), the highest number of genes (126) was assigned to ribosome, followed by purine metabolism (125 genes), spliceosome (104 genes), and pyrimidine metabolism (99 genes) (Fig. 1).

\section{Clustering of DEGs following algicide exposure}

Differential expression of genes in algicide-exposed cells was evaluated using the abundance of transcripts, quantified as FPKM. Contigs with FPKM lower than zero of were excluded from DEG analyses. Based on this cut-off

Table 2 Summary of annotation of contigs in each database

\begin{tabular}{lll}
\hline Public protein database & Number of contigs hits & Percentage (\%) \\
\hline NCBI NR & 82,749 & $43.28 \%$ \\
GO & 64,931 & $33.96 \%$ \\
KEGG & 29,983 & $15.60 \%$ \\
\hline
\end{tabular}




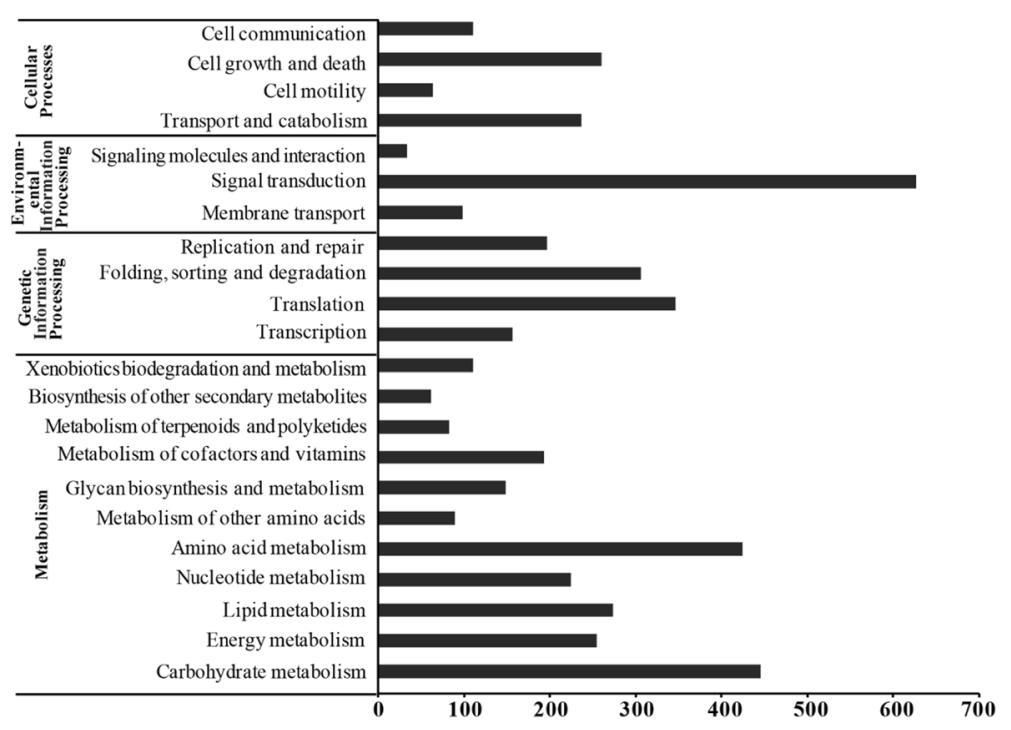

Fig. 1 Pathway assignment based on KEGG pathway analysis. The gene numbers were obtained from KEGG pathway online analysis

threshold, a total of 100,370 contigs were excluded, and 90,842 contigs were retained in subsequent analyses. Of these, 18,700 contigs (around $20.6 \%$ ) showed differentially expressed patterns, as determined by 2 -fold changes in expression. Of contigs with 2 -fold or greater changes in expression, 3816, 3430, and 5792 were up-regulated and 5304, 2530, 6052 were down-regulated at $12 \mathrm{~h}, 24 \mathrm{~h}$, and $48 \mathrm{~h}$, respectively (Additional file 4).

Based on $K$-mean clustering analysis, all contigs were divided into 8 clusters (Fig. 2; Additional file 5). Of these, clusters $1,3,5$, and 8 , which included 5573, 1023, 1933 , and 20 contigs, respectively, showed up-regulated patterns of expression within $48 \mathrm{~h}$ of algicide exposure. Of these four clusters, cluster 1 was the least upregulated, with a mean change in expression of around 2-fold and no obvious difference among tested samples. By contrast, expression of contigs in clusters 3 and 8 gradually increased over $48 \mathrm{~h}$, and cluster 8 had greatest increase in expression, which occurred at $48 \mathrm{~h}$. The contigs in cluster 5 were down-regulated at first and then expression gradually increased. Cluster 2 (1077 contigs), cluster 4 (6889 contigs), and cluster 7 (935 contigs) showed no obvious changes or down-regulation. In cluster 6 (1250 contigs), contigs generally displayed upregulation first and then down-regulation patterns; some contigs showed the highest expression level at $12 \mathrm{~h}$ or $24 \mathrm{~h}$ ( $>2$ fold changes), and then they showed decreased expression levels i.e., lesser than that of control. Other contigs showed increased expression levels i.e., more than that of control, and then decreased expression levels $>2$ fold changes at $48 \mathrm{~h}$.

The up- and down-regulated contigs with $>2$ fold changes were analyzed separately. Base on this criterion, we detected 848 up-regulated and 726 down-regulated contigs at all time intervals i.e., $12 \mathrm{~h}, 24 \mathrm{~h}$, and $48 \mathrm{~h}$ (Additional file 6). These data were then combined with $\mathrm{K}$-mean clustered contigs with 2 -fold changes in expression and overlapping contigs were removed before further analysis. The three up-regulated clusters (clusters 3, 5 , and 8 ) and $>2$-fold up-regulated contigs were pooled together into group 1 (3624 contigs in total); and cluster 6 and $>2$-fold down-regulated contigs were pooled together into group 2 (1976 contigs in total).

\section{Classification of DEGs by KEGG analysis}

The contigs that matched to bacteria and viruses were filtered out, and only eukaryote-matched contigs were subjected to further KEGG pathway analyses. This showed that 1130 eukaryote-matched contigs were assigned to group 1, and these contigs mapped to 157 KEGG pathways (Additional file 3) excluding organismal systems and human disease pathways (Fig. 3). These were assigned to metabolic processing (457 genes), genetic information processing (309 genes), environmental information processing (154 genes), and cellular processes (148 genes). The top three second level pathways were translation (154 genes) (Additional file 7), signal transduction (148 genes) (Additional file 8), and carbohydrate metabolism (122 genes). The top three third level pathways were ribosome (76 genes) (Additional file 7), spliceosome (41 genes) (Additional file 9), and oxidative phosphorylation (36 genes) (Additional file 10). Of interest was that in the transcription pathway analysis 47 genes were identified as spliceosome, but only 2 transcription factors were identified.

In group 2, we detected 374 eukaryote-matched contigs; of these, 133 were assigned to the KEGG database, and mapped to 77 KEGG pathways (Fig. 3, Additional 


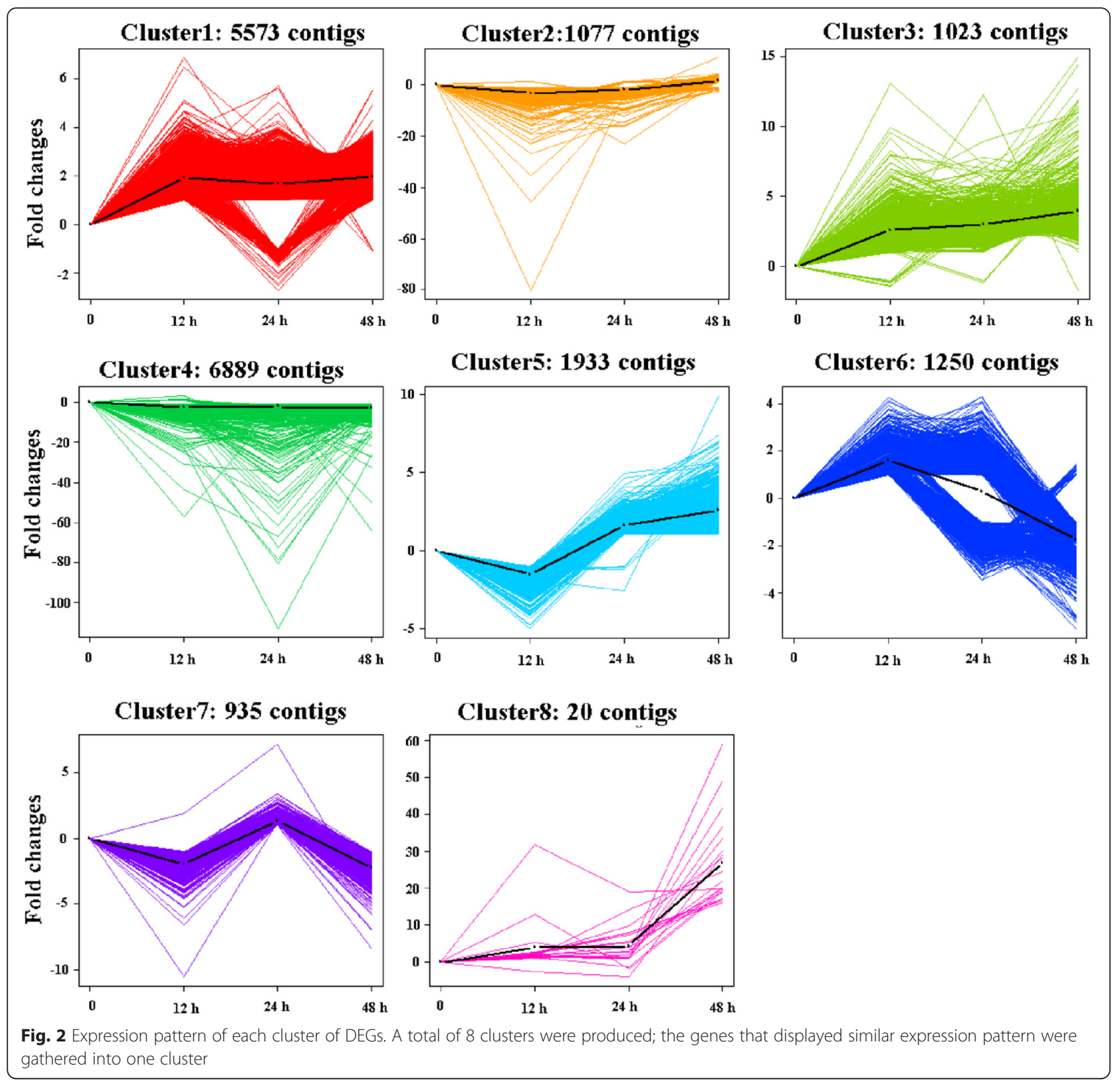

file 3) excluding organismal systems and human disease pathways These were assigned to metabolic processing (64 genes), genetic information processing (45 genes), environmental information processing (23 genes), and cellular processes (20 genes). The top three second level pathways were translation (26 genes) (Additional file 7), signal transduction (23 genes) (Additional file 8), and energy metabolism (16 genes). The top three third level pathways were ribosome (20 genes) (Additional file 7), photosynthesis (Additional file 11) (7 genes), and protein processing in endoplasmic reticulum (6 genes). In the transcription pathway, only one gene was assigned to the spliceosome pathway and no transcription factor was detected.
Photosynthetic and mitochondrial gene responses in $C$. polykrikoides

Using KEGG pathway analyses, we found that the most affected metabolic pathways were oxidative phosphorylation in group 1 (Additional file 10), and photosynthesis in group 2 (Additional file 11). Since not all the sequences were annotated in the KEGG database, we further characterized the genes, which were involved in photosynthetic light reaction and mitochondria, using $\mathrm{NR}$ and GO database annotation. In these analyses, contigs that coded for the same gene were counted as single genes.

Among regulated photosynthesis genes (Additional file 12; Fig. 4), most genes involved in photosystem I (PS I), 


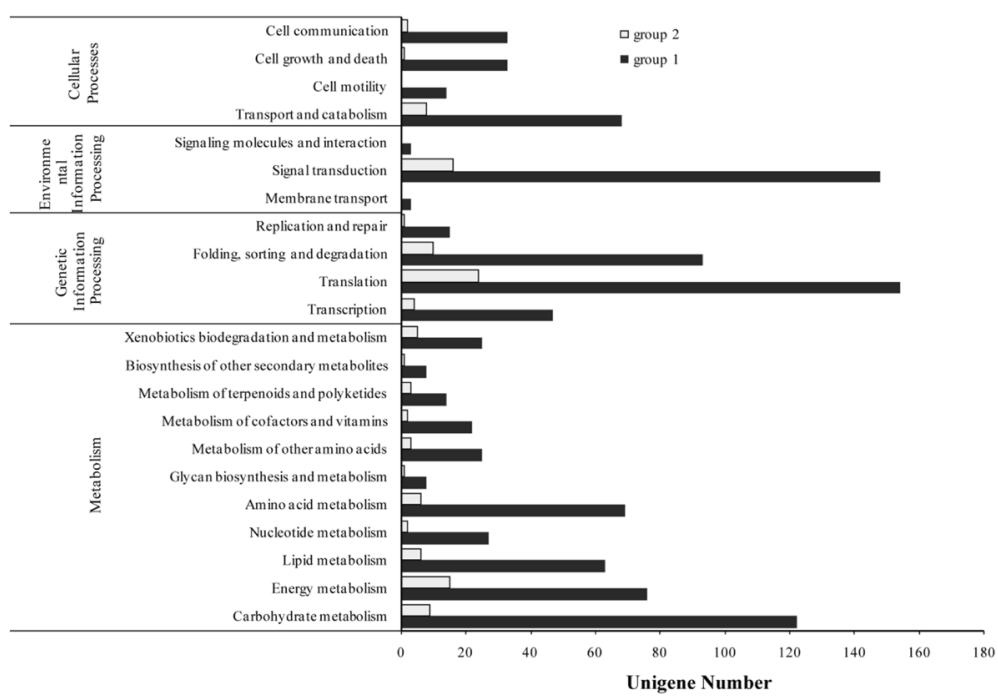

Fig. 3 The pathway assignment of DEGs by KEGG pathway analysis. Each group of DEGs was assigned to KEGG database, and gene numbers were got from KEGG online analysis

photosystem II (PS II), and cytochrome $b_{6} f$ complex showed patterns of down-regulation, particularly at $48 \mathrm{~h}$ after exposure to copper sulfate. Of a total of nine genes involved in the PS I complex, four genes were downregulated from $12 \mathrm{~h}$ to $48 \mathrm{~h}$ after algicide exposure. Other genes were up-regulated and showed highest expression levels at $12 \mathrm{~h}$, and then the expression levels were decreased. Transcriptional expression of the fifteen genes involved in the PS II complex gradually decreased from $12 \mathrm{~h}$ or increased at first, and then decreased; nine genes were down-regulated $>2$-fold at $48 \mathrm{~h}$. As for the chloroplast cytochrome $b_{6} f$ complex, two genes were down-regulated at $48 \mathrm{~h}$, and one gene was up-regulated by $>2$-fold at $12 \mathrm{~h}$, and expression then decreased. Differing from PS II, PS I, and cytochrome $b_{6} f$ complex, expression of most light-harvesting proteins was upregulated. Of seven light-harvesting protein genes, three genes were down-regulated $>2$-fold at least once (at one time point), and four genes were up-regulated $>2$-fold changes at least once. Of eleven photosynthetic electron transport associated genes, expression of four gradually decreased within $48 \mathrm{~h}$; expression of three increased at first and then decreased; two were up-regulated; and two were down-regulated and then increased expression, showing $>2$-fold changes at $48 \mathrm{~h}$.

Oxidative phosphorylation is a metabolic pathway that takes place in mitochondria. We examined behavior of certain mitochondrial associated genes which may contribute to mitochondrial composition or have mitochondrionrelated functions (Additional file 13; Fig. 5). Of a total of 132 of these genes, 107 were up-regulated by $>2$-fold. Focusing on mitochondrial complex (MC) I, II, III, IV, and V composition genes, some of MC I and II genes were slightly down-regulated; however, all MC I and II coding genes were up-regulated from $24 \mathrm{~h}$ after algicide exposure, attaining $>2$-fold changes at $48 \mathrm{~h}$. Expression of most of genes that coding for MC III component was increased, and only two genes showed down-regulation patterns. Overall, genes that code for MC IV and V showed up-regulation patterns. These results indicate that the mitochondrial genes examined participate in the cellular response to $\mathrm{CuSO}_{4}$ exposure.

\section{Antioxidant gene responses and copper function genes in C. polykrikoides}

Since $\mathrm{CuSO}_{4}$ is a potential reactive oxygen species (ROS) inducer, production of certain antioxidants involved in detoxifying ROS in cells may be affected following exposure. Hence, we examined the behavior of antioxidant genes, including those associated with peroxiredoxin (Prxs), glutathione S-transferase (GST), glutathione reductase $(G R)$, thioredoxin ( $\operatorname{Tr} x)$, etc. (Additional file 14; Fig. 6). Of these, expression of Prxs, GST, GR and Trx associated genes gradually increased following $\mathrm{CuSO}_{4}$ exposure (Fig. 6). In addition, some copper transporting and binding associated genes such as P-type ATPases were found to be expressed differentially (Additional file 15). Furthermore, widely studied chloroplast copper binding protein genes such as $\mathrm{Cu} / \mathrm{Zn}$ superoxide dismutase (SOD) showed downregulation patterns at $12 \mathrm{~h}$, and then expression increased a little. Mitochondrial copper binding protein related genes, such as cytochrome $\mathrm{C}$ oxidase subunit 17 (COX17), Scolp as well as some others were up-regulated following copper sulphate exposure (Additional file 13). 


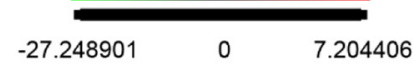

\begin{tabular}{|c|c|c|}
\hline 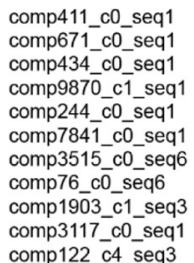 & $\begin{array}{l}\text { PetB } \\
\text { PetC } \\
\text { PetD } \\
\text { LHCA3 } \\
\text { LHCA2 } \\
\text { LHCA5 } \\
\text { LHB1B2 } \\
\text { LHB1B2 } \\
\text { LHCB6 } \\
\text { LHCB6 }\end{array}$ & Cytochrome $b_{\sigma} f$ complex \\
\hline
\end{tabular}

comp45192_c0_seq1

comp464_c0_seq2

comp464 c0 seq5

comp47109 c0 seq 1

comp80 c1 seq5

comp80_c1_seq8

comp118_c3_seq2

comp118_c3_seq8

comp227_c1seq2

comp227_c1_seq36

comp227_c1_seq62

comp227 c1 seq19

comp227 c1 seq4

comp227_c1_seq7

comp6824_c0_seq1

comp227_c1_seq31

comp558_c0_seq1

comp2483_c0_seq4

comp363_c0_seq1

comp363_c0_seq2

comp363 c0 seq 3

comp2996_c0_seq1

comp28316_c1_seq1

comp3443_c0_seq1

comp61_c0_seq1

comp651_c0_seq1

comp651_c0_seq1

comp575_c0_seq1

comp575_c0_seq2

comp4370_c0_seq 1

comp4370 c0 seq1

comp646 c0 seq7

comp2689 c0 seq 1

comp303_c0_seq2

comp23774_c0_seq1

comp777_c0_seq5

comp780 c0 seq 3

comp17154 c0 seq

comp14650_co_seq

comp73271_c0_seq

comp73271_co_sed

comp15_c0_seq1

comp253_c0_seq1

comp253_c0_seq

comp878_c0_seq

comp181_c0_seq1

comp796 c0 seq2

comp328 c0 seq6

comp $1389-1$

comp

comp1563_co_s

comp4181_c0_seq1

comp16898_c0_seq1

comp7420 c0 seq1

comp423_c0_seq1

comp425_c0_seq3

comp425 c0 seq7

comp423-

comp423_co_seq24

LHCB3

LHCB3

LHCB3

LHCB3

LHCB2

PetJ

PetJ

fer2

fer2

FNR 1

FNR 1

FNR 1

FNR 1

FNR 2

FNR 2

FNR2

FNR 2

PETH

ATPA

ATPC

ATPD

ATPD

ATPD

ATP5C1

ATPSC1

ATPF1A

ATPH

ATPH

PsaA

PsaA

PsaB

PsaB

PsaF

PsaF

PsaF

PsaL

PsaL

HCE1F

PsaC

PsaE1

ycf3

ycf4

NPQ1

PsbA2

PsbB

PsbB

PsbC

PsbD

PsbE

PsbL

Psb27

HCF136

PPL1

PsbK

$\mathrm{PsbF}$

PsbF

PsbO1

PsbV

PsbV

Psbo

PsbO2

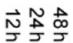

\section{Photosynthetic electron \\ transport}

\section{Photosystem I}

\section{Photosystem II}

Fig. 4 Heat map of DEGs that involved in the photosynthesis light reaction process. Log ratio fold changes were used as relative gene expression level compared to control. The full name of the gene and their characteristic were listed in the Additional file 12

qRT-PCR validation of DEGs identified by transcriptome sequencing

We selected 13 DEGs with $>2$ fold changes in expression (Additional file 1) and validated our results using qRTPCR (Fig. 7). Seven of these genes (ATPD - ATP synthase beta, PsbC- PSII CP43 apoprotein, PsaB - PSI
P700 apoprotein, $r b c L$ - ribulose 1,5-bisphosphate carboxylase oxygenase form II, PsbB- PSII CP47 apoprotein, $C O X 1$ - cytochrome oxidase subunit 1 , and $C Y B$ - cytochrome b) showed similar results to those obtained via RNA-Seq over the whole test period, with the same expression patterns, but relatively different expression 


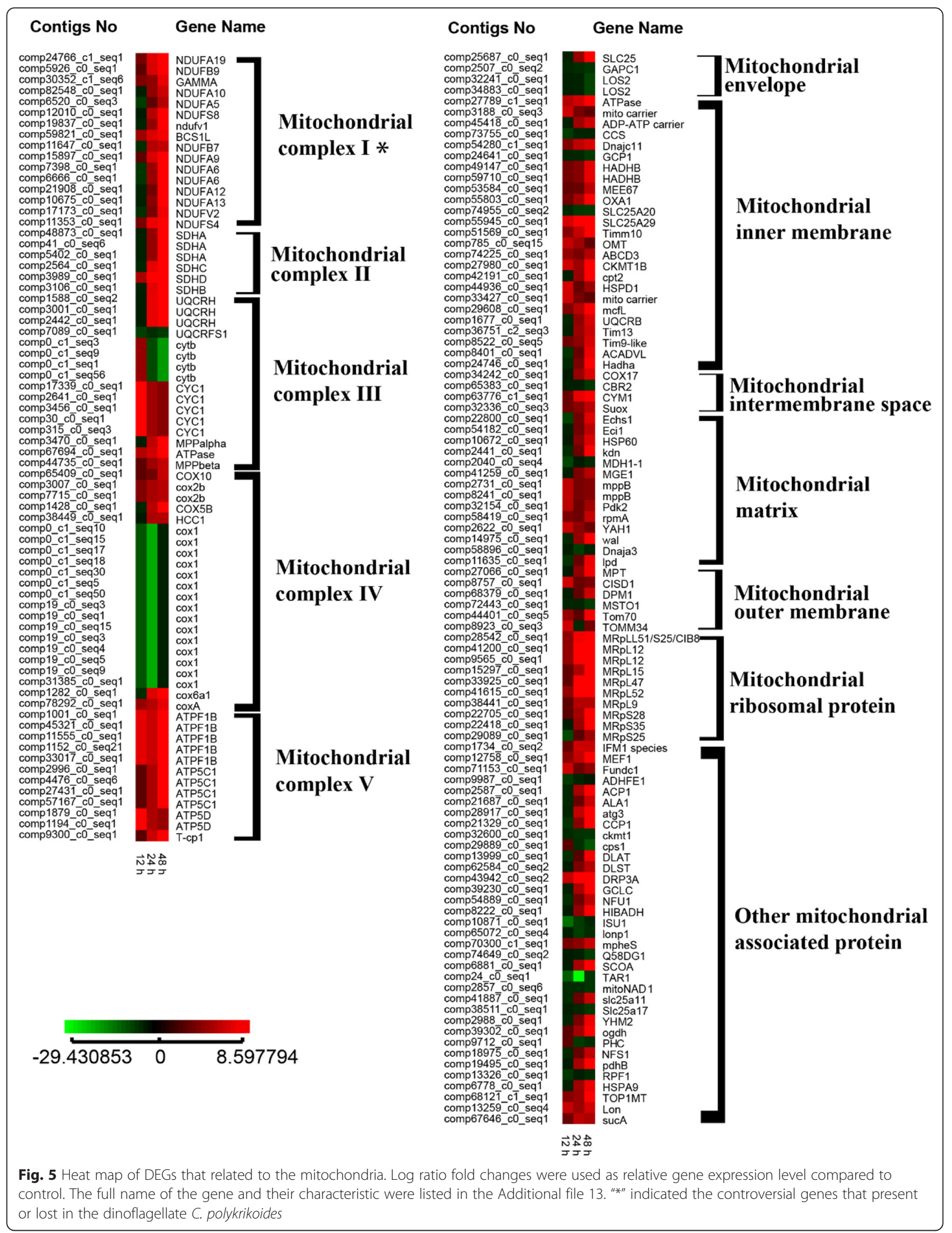




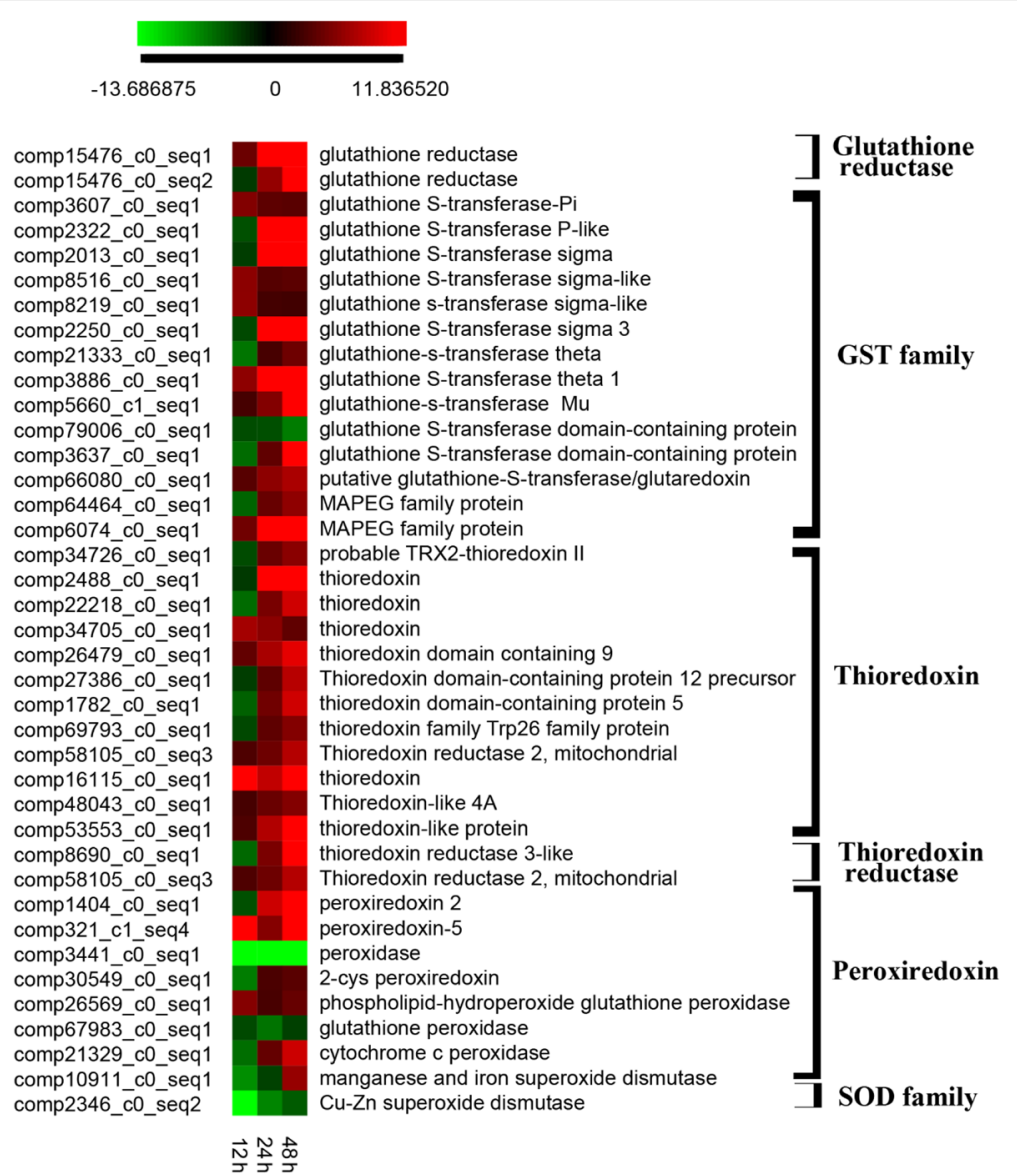

Fig. 6 Heat map of DEGs that are coded antioxidant enzymes. Log ratio fold changes were used as relative gene expression level compared to control. The full name of the gene was listed in the Additional file 14

levels. Of the other genes (FNR2 - chloroplast ferredoxin$\mathrm{NADP}(+)$ reductase 2, LHCB3- light-harvesting complex II $a / b$ binding protein $3, C T Y C 6 A$ - chloroplast cytochrome c6, PsbA2- PSII D1 reaction center protein, PetB cytochrome b6, and $P s b D$ - photosystem II protein D2), one or two tested samples (different time point) of each gene showed different expression patterns. Overall the results showed similar patterns of expression but with different strengths; the Spearman correlation coefficient $(R)$ of the tested samples was $0.69(N=39, P<0.001)$.

\section{The effect of $\mathrm{CuSO}_{4}$ on C. polykrikoides photosynthesis and lipid peroxidation}

Chlorophyll fluorescence parameters were monitored using a pulse amplitude modulation chlorophyll fluorometer. The maximal quantum efficiency of PS II $\mathrm{Fv} / \mathrm{Fm}$ in $C$. polykrikoides decreased considerably with increasing $\mathrm{CuSO}_{4}$ exposure time. In addition, $F \mathrm{v} / F_{\mathrm{O}}, \Psi \mathrm{Eo}_{\mathrm{o}}$, and $\Psi_{\mathrm{o}}$ gradually decreased with increasing exposure time to $\mathrm{CuSO}_{4}$ (Fig. 8).

The lipid peroxidation was increased in $C$. polykrikoides after $6 \mathrm{~h}$ and $72 \mathrm{~h} 1 \mathrm{mg} \mathrm{L}^{-1} \mathrm{CuSO}_{4}$ exposure (Additional file 16).

\section{Discussion}

HABs caused by the dinoflagellate Cochlodinium polykrikoides are a global concern due to their geographic expansion and harmful environmental impacts. However, molecular understanding of the species has received little attention compared to studies of the species focusing on environmental monitoring, physiology, and toxicology. Those studies of HAB-forming species addressing genetic aspects have focused on discovering genes responsible for toxin production and the effects of nutrient availability on the regulation [21, 24, 37, 38]. In this study, we characterized for the first time genomescale transcriptomes of C. polykrikoides, and further analyzed DEGs in response to algicide (copper sulfate) exposure to gain insights into the molecular mechanisms underlying the bloom termination process.

The effect of $\mathrm{CuSO}_{4}$ on the C. polykrikoides had been tested in several studies $[10,28]$. Although the same strain was employed in these studies, the sensitivity of the cell to $\mathrm{CuSO}_{4}$ was quite varied. Indeed, $C$. polykrikoides (CP-01) was very tolerant to $\mathrm{CuSO}_{4}$, and other contaminants as well in previous generations [28], the 


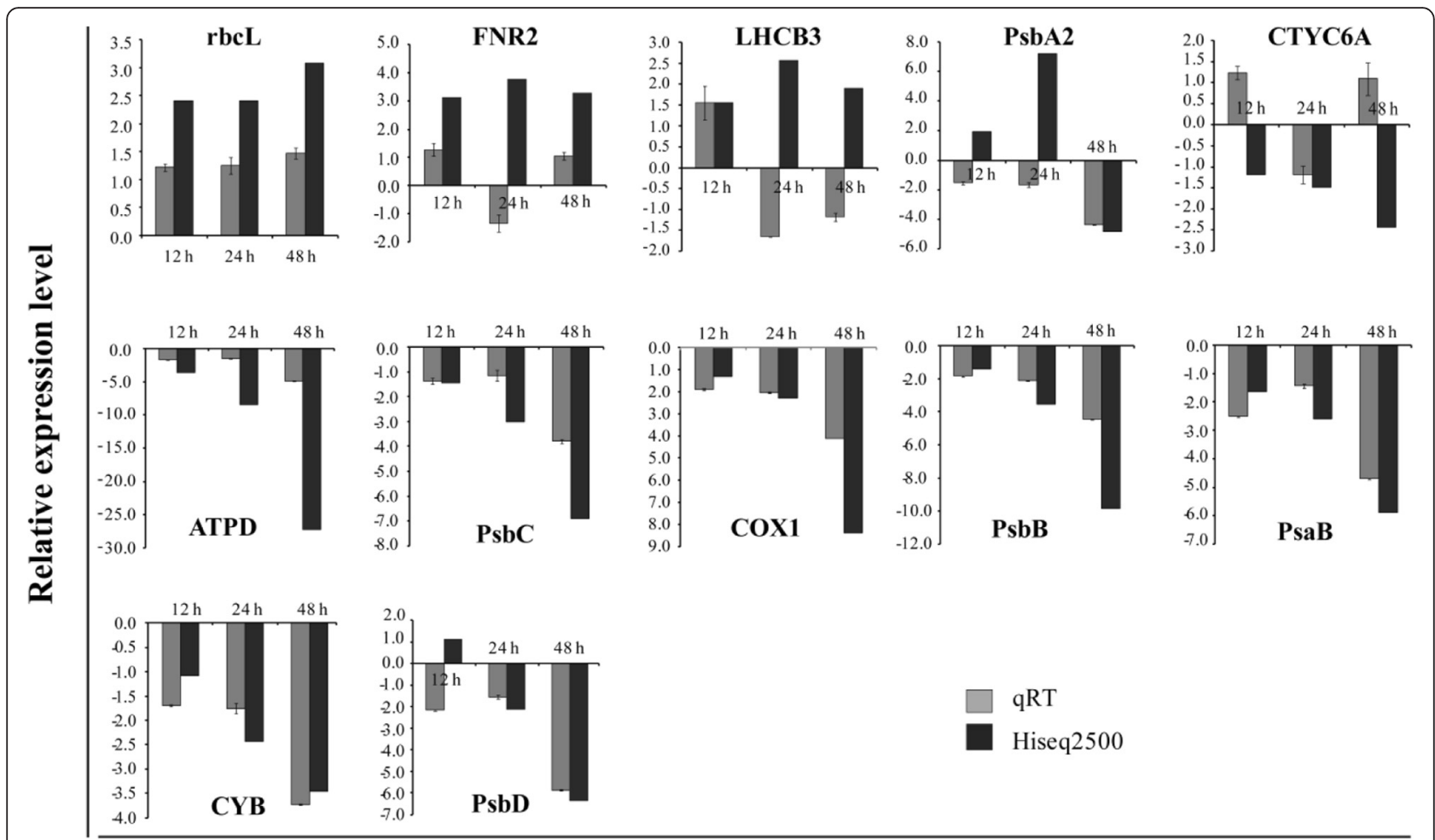

\section{Exposure time}

Fig. 7 qRT-PCR validation of 13 DEGs identified by RNA-Seq. The relative expression levels of $12 \mathrm{~h}, 24 \mathrm{~h}$, and $48 \mathrm{~h} \mathrm{CuSO}_{4}$ treated sample were presented. The housekeeping gene a-tubulin (TUA) was used as an internal control for qRT-PCR normalization. The relative expression level of control was considered as 1 , and the control samples were not shown in the figure

tolerance was decreased in more recent generations [10]. The reason might due to differential composition of multi-clone that happened after several successive transfers. Due to clonal variation, the reduction of Daphnia magna quite varied after stressor exposure like cadmium or cyanobacteria Microcystis aeruginosa [39]. In this study, the $\mathrm{CuSO}_{4}$ concentration we have selected was 10 times lower than that of 72 h-EC ${ }_{50}$ [28]. Furthermore, the copper concentration, we selected by considering the World Health Organization's guideline for copper in drinking water, which was $2.0 \mathrm{mg} / \mathrm{L}$ [40].

With the functional annotations presently available in three databases used (NR, GO, KEGG), few contigs could be annotated. The highest number of annotations $(82,749$ contigs, $43.3 \%)$ was obtained from the NR database. One of reason for this was that some contigs were generated by non-coding 5'- or 3'- untranslated regions, another reason might be the presence of many 'no-hit' contigs, belonging to undiscovered novel genes and/or non-coding RNAs (e.g., miRNA, siRNA, and rRNA), that are known to be present in dinoflagellates [41, 42]. However, these annotation success rates were higher than those from available transcriptome data for other dinoflagellates, including Alexandrium catenella and
Symbiodinium minutum $[16,23]$. This suggests that the enough of the functional genes in C. polykrikoides might have been identified in our experiments to sufficiently characterize the whole genome response of the species.

The KEGG pathway analysis provided physiological pathway information for C. polykrikoides. The KEGG pathways of C. polykrikoides were quite different from those of other dinoflagellates. For example, in A. catenella spliceosome, translation factor, and RNA transport were the top pathways [23]. However, in both of $C$. polykrikoides and $A$. catenella, many genes that were assigned to genetic metabolism or genetic information processes were identified. In addition, both species have many genes assigned to spliceosome, indicating that spliceosome is likely to be crucial in dinoflagellate genetic processes such as RNA-splicing. These transcriptome data provided basic genetic information on C. polykrikoides, however, further investigations on the characteristics and functions of C. polykrikoides genes are essential.

The mechanism of spliced trans-splicing of mRNA and no typical recognized promoter in the dinoflagellates implied that the dinoflagellate genes expression were regulated by post-transcriptional regulation [15, 43, 44]. Furthermore, investigations on some genes and their protein 

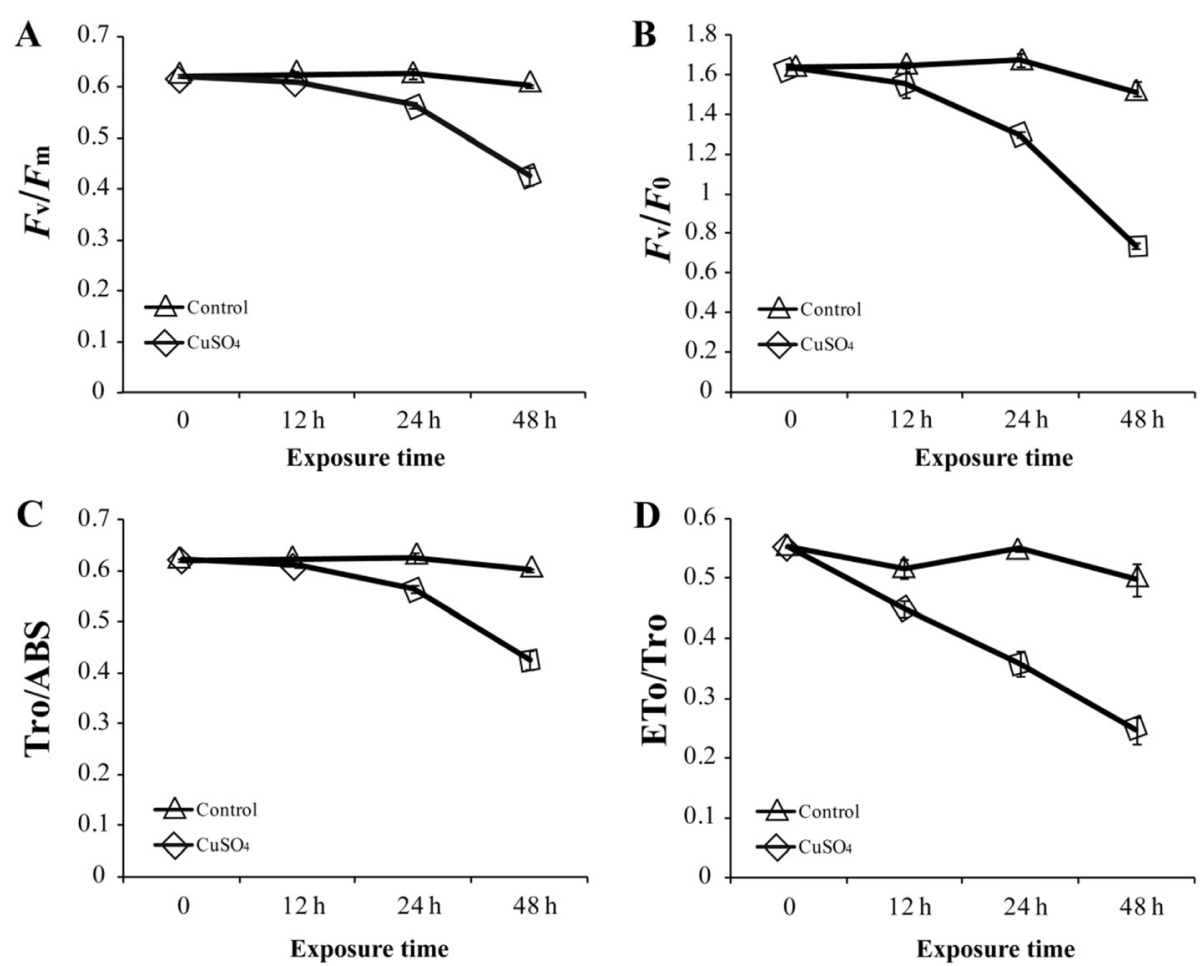

Fig. 8 Photosynthesis parameters of C. polykrikoides. a FV/Fm, maximum quantum efficiency of photosystem Il; b FV/FO, a value that is proportional to the activity of the water-splitting complex on the donor side of the PS I; c TRo/ABS (UEO), represents the maximum yield of primary photochemistry; d Eto/Tro $\left(\Psi_{0}\right)$ represents the efficiency with which a trapped exciton can move an electron into the electron transport chain beyond $\mathrm{Q}^{-}$

expressions revealed that they were regulated at protein level. These data were consistent with the posttrancriptional regulation hypothesis $[17,45,46]$. In addition, the low amount of transcriptome were identified in response to stress conditions in some dinoflagellates, for example, Pyrocystis lunula microarray studies showed that around $5.8 \%$ of DEGs (204 in total of 3500 genes) responded to nitrite, and $1.1 \%$ genes to the herbicide paraquat [18]. These data showed that dinoflagellates have no expression preference for transcriptional gene regulation pattern. However, the little higher expression amount transcriptome were also found in some dinoflagellates. For example, transcriptome analyses of Alexandrium fundyense showed that $10 \%$ of signature genes were differentially expressed at two different nutrient conditions [19]. More recently, Johnson et al. [22] reported $29 \%$ of genes were differentially expressed among different life stages in the dinoflagellate Karenia brevis. We detected that expression of $20.6 \%$ of contigs changed following exposure to the algicide $\mathrm{CuSO}_{4}$. In this context, the percentage of response to $\mathrm{CuSO}_{4}$ in this study was not low; this percentage was similar or higher than that shown in other dinoflagellates, suggesting that the algicide might considerably affect molecular genomic processes in $C$. polykrikoides. These HiSeq results were validated in a separate qRT-PCR assay, with significant correlation $\left(R^{2}=0.69, P<0.05\right)$ between results from the two methods.

Environmental stress can cause rapid changes in the production of cellular proteins for survival, and responses are controlled at multiple levels, including transcriptional, post-transcriptional, and translational levels [47]. As a protein involved in genetic processes, ribosome is central to the translation process; ribosomal proteins have functions not only in ribosome composition, but also involved in various regulation processes. Hence, their expression is regulated to balance the protein production in response to environmental changes [48, 49]. In this study, KEGG pathway analyses showed that many ribosomal protein genes were regulated by $\mathrm{CuSO}_{4}$. Similar results have been found in other various organisms, such as fungi, plants, and algae [48, 49]. For example, the ribosomal protein $\mathrm{L} 44$ gene was upregulated by salt, sorbitol, and heavy metal exposure in the fungus Aspergillus glaucus [49]. Differential expression of cytosolic ribosomal protein genes was induced by $\mathrm{CuCl}_{2}$ in marine algae Ulva compressa [50], by various environmental conditions (elevated sugar, nitrogen stress, and UV exposure) in Arabidopsis thaliana [48], and even at different life stages of the dinoflagellate $K$. 
brevis [22]. In this study, we found that some differentially expressed ribosomal protein genes, such as those coding for ribosomal proteins L44 (RPL44) and RPL11, were up-regulated by exposure to $\mathrm{CuSO}_{4}$. Taken together with previous findings, our results suggest that ribosomal protein genes (e.g., RPL44, RPL11) may be involved in cellular regulation in response to algicide exposure in dinoflagellates.

Transcription factors commonly regulate gene transcription in various cellular processes [51, 52]. In this study, only a few transcription factors were detected by DEG analysis. This implies that transcription factors were not widely involved in the gene regulation of $C$. polykrikoides when exposed to $\mathrm{CuSO}_{4}$. This provides further evidence of unusual gene regulation patterns in dinoflagellates, and highlights the need for further investigation of the mechanisms of gene regulation in this group. Nevertheless, these findings suggest that the algicide $\mathrm{CuSO}_{4}$ may disrupt gene transcription and translation in C. polykrikoides, slowing cell growth, accelerating cell death, and thereby inducing HAB termination.

Genes involved in photosynthesis in plants and algae are sensitive to various environmental stimuli, such as excess light, salinity, metals, etc. [53-55]. The transcription of photosystem genes was decreased in the diatom Ceratoneis closterium when exposed to copper [53] and in the green algae Chlorella when treated with $\mathrm{Pb}^{2+}[55]$. In our DEG analyses, core photosystem coding proteins (e.g., PsaA and PsaB of PS I, PsbB of PS II) were also down-regulated at $12 \mathrm{~h}$ after algicide exposure. In contrast, expression of some other photosynthesis-related genes, such as those coding for light harvesting proteins (e.g. LHB3, LHB6), along with PsaC (PS I), and PsbF (PS II) was increased. Similar results have been found in salt stressed rice, the opposite alteration of genes expression pattern of PsaD genes and other tested genes including PsaH, LHCA1, LHCA2 and LHCA4 were found in the salt stressed rice [56]. In addition, in herbicide (atrazine, bentazon) treated soybean expression of PS II type I and type II chlorophyll $a / b$ binding proteins was decreased, while $P s b R$ and $P s b S$ genes, and the oxygen evolving complex were up-regulated [57]. In dichloromethane and dichloroethane treated cells of the algae Chlorella, PsaB genes were up-regulated in the first $12 \mathrm{~h}$, but were downregulated after $24 \mathrm{~h}$ [58]. These results suggest that differential expression of photosystem genes under stress, and that in C. polykrikoides the photosystem apparatus (e.g., PS I and PS II) may be experience ongoing damage with increasing exposure time and doses of $\mathrm{CuSO}_{4}$.

The damage of photosystem by $\mathrm{CuSO}_{4}$ was also supported by our results showing the gradually decreasing photosynthetic efficiency (Fig. 8). This is in accordance with the results of previous research, which showed reduction in both $F \mathrm{v} / F \mathrm{~m}$ and $F \mathrm{v} / F \mathrm{o}$ in the black mangle when exposed to copper [59]. Additionally, in the red algae Antithamnion plumula, Fv/Fm decreased and PS II activity gradually decreased with exposure to increasing concentrations of $\mathrm{Cu}^{2+}$ [60]. These findings, taken together with the results of this study, suggest that excess $\mathrm{Cu}^{2+}$ might affect photosystem gene regulation and inhibit photosynthetic efficiency in dinoflagellates. These adverse effects might be due the direct damage to PS II or the inhibition of PS II repair mechanisms [61].

In contrast to photosynthesis-associated genes, we found that most mitochondrial genes were up-regulated in C. polykrikoides when exposed to $\mathrm{CuSO}_{4}$ (see Fig. 5). This is in agreement with the results of a previous study showing that the mitochondrial genes COX11 and COX17 were up-regulated in the algae Ulva compressa when exposed to copper [50]. This increased expression of mitochondrial genes may take place due to damage to mitochondrial proteins [50], or to boost oxidative phosphorylation to increase the probability of cell survival [62, 63]. In addition, many stress responses, such as rebalancing of cellular metabolite concentrations and altered ROS abundance, can be related to mitochondrial processes [63]. Robust mitochondrial function may be crucial to the survival of C. polykrikoides following algicide exposure, and prevention of reduced photosynthetic efficiency depends upon proper mitochondrial function under such stress conditions [63].

Mitochondria and photosystem require copper for their metabolic functions; however, excess copper can induce ROS production and is toxic to most organisms $[64,65]$. Indeed, the disturbance of mitochondria and photosynthesis-related genes is an indication of induced ROS production, since these are the organelles that produce intracellular ROS [62, 66]. In this study, we measured ROS production in C. polykrikoides exposed to copper using fluorescence spectrometry. However, we could not quantify the exact amounts of ROS produced, because the naked $\mathrm{CuSO}_{4}$ treated dinoflagellate cells were highly fragile and were easily destroyed during ROS sample preparation. This considerable ROS production was in agreement with the results obtained for another dinoflagellate, Prorocentrum minimum, exposed to the same algicide, $\mathrm{CuSO}_{4}[65,67]$. It is likely that that copper induces oxidative stress by facilitating the generation of ROS, and high doses of copper damage C. polykrikoides cells irreversibly [10, 65].

Such cellular oxidative stress can be mitigated by the activation of antioxidant systems [68]. The main antioxidants include glutathione (GSH), thioredoxin (Trxs), peroxiredoxin (Prx), superoxide dismutase (SOD), and catalase [10, 69-71]. In this study, most up-regulated antioxidant genes were related to GSH, Trxs, and Prx production. The up-regulation of antioxidant enzyme (e.g. Prx, Trxs, and GSH) production was increased 
following copper exposure in the marine algae Ulva compressa [50] and also in the dinoflagellate P. minimum [65]. In particular, Glutathione S-transferase (GST) is a large gene superfamily, the members of which function as antioxidants by conjugating GSH to toxic substances. In addition, differential transcriptional expression of GST members in response to variation in environmental conditions has been found in various organisms $[65,72,73]$. Increased expression of MAPEG (membrane-associated proteins in eicosanoid and glutathione metabolism) family members has been reported in $P$. minimum in response to exposure to $\mathrm{CuSO}_{4}$ [65]. In addition, reduced GSH production was increased in P. minimum cells treated with $\mathrm{CuSO}_{4}$ [65]. These results suggest that in dinoflagellates GST genes may play an important role in cellular responses to $\mathrm{CuSO}_{4}$ induced stress.

The thioredoxin system includes two antioxidants, Trxs and thioredoxin reductase (TrxR) [74]. Trxs is a protein with a conserved redox site that maintains the intracellular redox state and reduces protein thiols. TrxR is required for the reduction of the active disulfide site in Trx, and plays a role in redox regulation [69]. Prxs family genes also function by via a thiol redox mechanism; they respond to various environmental stresses, such as $\mathrm{H}_{2} \mathrm{O}_{2}$, high light, and nutrient deprivation, and they are sensitive to cellular oxidation [75]. Hence, the accumulation of oxidized Prxs may indicate disruption of cellular redox homeostasis $[75,76]$. The regulation of $\operatorname{Tr} x$ and $\operatorname{Tr} x R$, as well as Prxs genes may be involved in the response of C. polykrikoides to $\mathrm{CuSO}_{4}$. Similarly, the copper induced expressions of thioredoxin and Prxs genes or their proteins were found in other organisms. For example, the expression of thioredoxin increased by copper in brown algae Ectocarpus siliculosus [77]; expression level of Prx protein increased by copper in macroalgae Scytosiphon gracilis [78]; the Prx enzyme activity was increased in brown alga Dictyota kunthii by excess copper [79]. Furthermore, Prx likely acted as an active antioxidant to control lipid peroxidation generated by copper in the S. gracilis and D. kunthii [78, 79]. Corresponding to increased Prxs gene expression, the lipid peroxidation increased in C. polykrikoides after $\mathrm{CuSO}_{4}$ exposure, which suggests that the Prxs might function in lipid peroxidation by decreasing $\mathrm{CuSO}_{4}$ induced stress in C. polykrikoides. Because glutathione, thioredoxin, Prxs are all elements of the thiol-disulfide redox regulatory network. This suggests that the thioldisulfide redox system might play a vital role in the $\mathrm{CuSO}_{4}$ induced stress defense network in dinoflagellates.

\section{Conclusions}

This study is the first to report transcriptome profiles of the dinoflagellate $C$. polykrikoides with a focus on the genome-wide molecular responses to the biocide $\mathrm{CuSO}_{4}$. $\mathrm{CuSO}_{4}$ significantly decreased photosynthetic efficiency and induced widespread regulation of gene networks and signal transduction pathways in C. polykrikoides cells. DEG analyses showed that various photosynthetic genes were regulated in C. polykrikoides exposed to $\mathrm{CuSO}_{4}$. Based on these results, we conclude that the photosynthetic machinery might be severely affected when treated with the algicide, leading cell death. In addition, gene translation and transcription processes may be disturbed, and this may further inhibit cell growth and proliferation, possibly accelerating cell death. However, antioxidant systems and mitochondrial genes are likely to be activated in response to the cellular stress caused by $\mathrm{CuSO}_{4}$ exposure, and this might compensate for the decrease in photosynthetic efficiency. These results provide an understanding of the molecular basis of the cellular and genomic responses of HAB forming dinoflagellate cells exposed to algicides, and of the $\mathrm{HAB}$ termination process.

\section{Additional files}

Additional file 1: The primers and full name of genes that used in the qRT-PCR validation. (XLSX $12 \mathrm{~kb}$ )

Additional file 2: The contigs length distribution of the $\boldsymbol{C}$. polykrikoides transcriptome. The gray bar indicated the total contigs, and white indicated contigs that have annotation in NR database. (PPTX $174 \mathrm{~kb}$ )

Additional file 3: KEGG pathways of DEGs. The third level pathways of group 1 and group 2 were list in the excel file. Gene numbers indicated the total gene numbers that assigned to each third level pathway. (XLSX $16 \mathrm{~kb}$ )

Additional file 4: The numbers of DEGs. The DEGs numbers with 2.0-fold cut-off at 12 h, 24 h, and 48 h. (PPTX 82 kb)

Additional file 5: $K$-means clustering heat map of DEGs. Total 8 clusters were shown; the cluster 8 was not recognized clearly since there were only 20 contigs. (PPTX $187 \mathrm{~kb}$ )

Additional file 6: Analysis of contigs showing fold change more than 2.0-fold. (A) Up-regulation; (B) Down-regulation. (PPTX $157 \mathrm{~kb}$ )

Additional file 7: DEGs that involved in translation. The genes were identified by KEGG pathway analysis. (XLSX 37 kb)

Additional file 8: DEGs that involved in signal transduction. The genes were identified by KEGG pathway analysis. (XLSX 34 kb)

Additional file 9: DEGs that involved in spliceosome. The genes were identified by KEGG pathway analysis. (XLSX $14 \mathrm{~kb}$ )

Additional file 10: DEGs that involved in oxidative phosphorylation. The genes were identified by KEGG pathway analysis. "**" indicated the controversial genes that present or lost in the dinoflagellate $C$. polykrikoides. (XLSX $17 \mathrm{~kb}$ )

Additional file 11: DEGs that involved in photosynthsis. The genes were identified by KEGG pathway analysis. (XLSX 12 kb)

Additional file 12: Differentially expressed photosynthesis related genes. The genes were manually summarized by reviewing GO and NR annotation. (XLSX $22 \mathrm{~kb}$ )

Additional file 13: Differentially expressed mitochondria related genes. The genes were manually summarized by reviewing GO and NR annotation. "** indicated the controversial genes that present or lost in the dinoflagellate C. polykrikoides. (XLSX 34 kb) 
Additional file 14: Differentially expressed antioxidant genes. The genes were manually summarized by reviewing $G O$ and NR annotation. (XLSX $14 \mathrm{~kb}$ )

\section{Additional file 15: Differentially expressed copper binding or} transport genes. The genes were manual summarized by reviewing $\mathrm{GO}$ and NR annotation. (XLSX 14 kb)

Additional file 16: Lipid peroxidation levels. Lipid peroxidation levels expressed as malondialdehyde (MDA) C. polykrikoides after 6 and $72 \mathrm{~h}$ exposure. Significant differences between the control and treated groups, as determined using one-way ANOVA, are highlighted ${ }^{* *} P<0.01$. (PPTX $163 \mathrm{~kb}$ )

\section{Abbreviations}

ATPD: ATP synthase beta; COX $(11 ; 17)$ : Cytochrome c oxidase assembly protein subunit $(11 ; 17) ; \mathrm{COX} 1$ : Cytochrome oxidase subunit 1; $\mathrm{CuSO}_{4}$ : Copper sulfate; CYB: Cytochrome b; CYTC6A: Chloroplast cytochrome c6; DEGs: Differentially expressed genes; FNR2: Chloroplast ferredoxin$\mathrm{NADP}(+)$ reductase; FPKM: Fragments per kilobase of transcript per million mapped reads; GO: Gene ontology; GSH: Glutathione; GST: Glutathione Stransferase; HABs: Harmful algal blooms; KEGG: Kyoto Encyclopedia of Genes and Genomes; LHCA $(1,2,4)$ : Light-harvesting complex I chlorophyll a/b binding protein $(1,2,4)$; LHCB $(3,6)$ : Light-harvesting complex II chlorophyll a/b binding protein $(3,6)$; MC: Mitochondrial complex; PetB: cytochrome b6; NR: Non-redundant protein; Prx: Peroxiredoxin; PS I: Photosystem I; PS II: Photosystem II; PsaA: PS I P700 chlorophyll a apoprotein A1; PsaB: PSI P700 apoprotein A2; PsaC: PS I subunit VII; PsaD: PS I subunit II; PsaH: PS I subunit VI; PsbA2: PSII D1 reaction center protein; PsbB: PSII CP47 apoprotein; PsbC: PSII CP43 apoprotein; PsbD: photosystem II protein D2; PsbF: PS I| cytochrome b559 subunit beta; PsbR: PS II cytochrome b559 subunit beta; PsbS: PS II 22 kDa protein; rbcL: Ribulose 1,5-bisphosphate carboxylase oxygenase form II; SBH: Single-directional best hit; SOD: Superoxide dismutase; TrxR: Thioredoxin reductase; Trxs: Thioredoxin.

\section{Competing interests}

The authors declare that they have no competing interests.

\section{Authors' contributions}

RYG performed the experiments, analyzed the data, and wrote the manuscript; WH performed the experiments and analyzed the data; YSS contributed to the experimental idea, provided reagents and materials; SJK conceived and designed project, analyzed the data, and wrote the manuscript. All the authors read and approved the final manuscript.

\section{Acknowledgement}

This work was supported by the National Research Foundation of Korea Grant funded by the Korean Government (2013R1A1A2013596, and 2015M1A5A1041805), and by a grant from the National Fisheries Research and Development (R2015047) funded to J.-S. Ki.

\section{Author details}

'Department of Life Science, College of Natural Sciences, Sangmyung University, Seoul 110-743, Korea. ${ }^{2}$ Fishery and Ocean Information Division, National Fisheries Research \& Development Institute, Busan 619-705, Korea.

\section{Received: 24 June 2015 Accepted: 22 December 2015}

Published online: 05 January 2016

\section{References}

1. Taylor FJR, Hoppenrath M, Saldarriaga J. Dinoflagellate diversity and distribution. Biodivers Conserv. 2008;17(2):407-18.

2. Anderson DM, Cembella AD, Hallegraeff GM. Progress in understanding harmful algal blooms: paradigm shifts and new technologies for research, monitoring, and management. Ann Rev Mar Sci. 2012;4:143-76.

3. Glibert PM, Icarus Allen J, Artioli Y, Beusen A, Bouwman L, Harle J, et al. Vulnerability of coastal ecosystems to changes in harmful algal bloom distribution in response to climate change: projections based on model analysis. Glob Chang Biol. 2014;20(12):3845-58.

4. Miao C, Tang Y, Zhang H, Wu Z, Wang X. Harmful algae blooms removal from fresh water with modified vermiculite. Environmental Technolog. 2014;35(1-4):340-6.
5. Smayda TJ. What is a bloom? A commentary. Limnol Oceanogr. 1997; 42(5part2):1132-6.

6. Harvey EL, Menden-Deuer S. Predator-induced fleeing behaviors in phytoplankton: a new mechanism for harmful algal bloom formation? PLoS ONE. 2012;7(9):e46438.

7. Kim HG. Mitigation and controls of HABs. In: Graneli E, Turner J, editors. Ecology of harmful algae, vol. 189. Springer Verlag, Berlin, Heidelberg; 2006. p. 327-38.

8. Secher S. Measures to control harmful algal blooms. The Plymouth Student Scientist. 2009;2(1):212-27.

9. Qian H, Yu S, Sun Z, Xie X, Liu W, Fu Z. Effects of copper sulfate, hydrogen peroxide and $\mathrm{N}$-phenyl-2-naphthylamine on oxidative stress and the expression of genes involved photosynthesis and microcystin disposition in Microcystis aeruginosa. Aquat Toxicol. 2010;99(3):405-12.

10. Ebenezer V, Lim WA, Ki J-S. Effects of the algicides $\mathrm{CuSO}_{4}$ and $\mathrm{NaOCl}$ on various physiological parameters in the harmful dinoflagellate Cochlodinium polykrikoides. J Appl Phycol. 2014;26(6):2357-65.

11. Gouvêa SP, Boyer GL, Twiss MR. Influence of ultraviolet radiation, copper, and zinc on microcystin content in Microcystis aeruginosa (Cyanobacteria). Harmful Algae. 2008:7(2):194-205.

12. Jeong HJ, Kim HR, Kim Kl, Kim KY, Park KH, Kim ST, et al. $\mathrm{NaOCl}$ produced by electrolysis of natural seawater as a potential method to control marine red-tide dinoflagellates. Phycologia. 2002;41(6):643-56.

13. Hackett JD, Bhattacharya D. The genomes of dinoflagellates. In: Katz LA, Bhattacharya D, editors. Genomics and evolution of microbial eukaryotes. New York: Oxford University Press; 2006. p. 48-63.

14. Hackett JD, Anderson DM, Erdner DL, Bhattacharya D. Dinoflagellates: a remarkable evolutionary experiment. Am J Bot. 2004;91(10):1523-34.

15. Zhang H, Hou Y, Miranda L, Campbell DA, Sturm NR, Gaasterland T, et al. Spliced leader RNA trans-splicing in dinoflagellates. Proc Natl Acad Sci. 2007:104(11):4618-23.

16. Shoguchi E, Shinzato C, Kawashima T, Gyoja F, Mungpakdee S, Koyanagi R, et al. Draft assembly of the Symbiodinium minutum nuclear genome reveals dinoflagellate gene structure. Curr Biol. 2013;23(15):1399-408.

17. Brunelle SA, Van Dolah FM. Post-transcriptional regulation of s-phase genes in the dinoflagellate, Karenia brevis. J Eukaryot Microbiol. 2011;58(4):373-82.

18. Okamoto OK, Hastings J. Novel dinoflagellate clock-related genes identifed through microarray analysis. J Phycol. 2003;39(3):519-26.

19. Erdner DL, Anderson DM. Global transcriptional profiling of the toxic dinoflagellate Alexandrium fundyense using massively parallel signature sequencing. BMC Genomics. 2006;7(1):88.

20. Moustafa A, Evans AN, Kulis DM, Hackett JD, Erdner DL, Anderson DM, et al. Transcriptome profiling of a toxic dinoflagellate reveals a gene-rich protist and a potential impact on gene expression due to bacterial presence. PLoS ONE. 2010;5(3), e9688.

21. Yang I, Beszteri S, Tillmann U, Cembella A, John U. Growth-and nutrientdependent gene expression in the toxigenic marine dinoflagellate Alexandrium minutum. Harmful Algae. 2011;12:55-69.

22. Johnson JG, Morey JS, Neely MG, Ryan JC, Van Dolah FM. Transcriptome remodeling associated with chronological aging in the dinoflagellate, Karenia brevis. Mar Genomics. 2012;5:15-25.

23. Zhang S, Sui Z, Chang L, Kang K, Ma J, Kong F, et al. Transcriptome de novo assembly sequencing and analysis of the toxic dinoflagellate Alexandrium catenella using the Illumina Platform. Gene. 2014:537(2):285-93.

24. Morey JS, Monroe EA, Kinney AL, Beal M, Johnson JG, Hitchcock GL, et al. Transcriptomic response of the red tide dinoflagellate, Karenia brevis, to nitrogen and phosphorus depletion and addition. BMC Genomics. 2011;12(1):346.

25. Kudela RM, Gobler CJ. Harmful dinoflagellate blooms caused by Cochlodinium sp.: Global expansion and ecological strategies facilitating bloom formation. Harmful Algae. 2012;14:71-86.

26. Kim CS, Lee SG, Lee CK, Kim HG, Jung J. Reactive oxygen species as causative agents in the ichthyotoxicity of the red tide dinoflagellate Cochlodinium polykrikoides. J Plankton Res. 1999:21(11):2105-15.

27. Gárate-Lizárraga I, López-Cortes DJ, Bustillos-Guzman JJ, Hernández-Sandoval F. Blooms of Cochlodinium polykrikoides (Gymnodiniaceae) in the gulf of California, Mexico. Rev Biol Trop. 2004;52 Suppl 1:51-8.

28. Ebenezer $\mathrm{V}, \mathrm{Ki} \mathrm{J}$-S. Evaluation of the sub-lethal toxicity of $\mathrm{Cu}, \mathrm{Pb}$, bisphenol $\mathrm{A}$ and polychlorinated biphenyl to the marine dinoflagellate Cochlodinium polykrikoides. Algae. 2012;27(1):63-70.

29. Grabherr MG, Haas BJ, Yassour M, Levin JZ, Thompson DA, Amit I, et al. Full-length transcriptome assembly from RNA-Seq data without a reference genome. Nat Biotechnol. 2011;29(7):644-52. 
30. Kanehisa M, Araki M, Goto S, Hattori M, Hirakawa M, Itoh $M$, et al. KEGG for linking genomes to life and the environment. Nucleic Acids Res. 2008;36 suppl 1:D480-4.

31. Conesa A, Götz S, García-Gómez JM, Terol J, Talón M, Robles M. Blast2GO: a universal tool for annotation, visualization and analysis in functional genomics research. Bioinformatics. 2005;21(18):3674-6.

32. Kriedemann $P$, Graham $R$, Wiskich J. Photosynthetic dysfunction and in vivo changes in chlorophyll a fluorescence from manganese-deficient wheat leaves. Aust J Agr Res. 1985;36(2):157-69.

33. Kalaji HM, Bosa K, Kościelniak J, Żuk-Gołaszewska K. Effects of salt stress on photosystem II efficiency and $\mathrm{CO}_{2}$ assimilation of two Syrian barley landraces. Environ Exp Bot. 2011;73:64-72.

34. Ebenezer V, Ki J-S. Biocide sodium hypochlorite decreases pigment production and induces oxidative damage in the harmful dinoflagellate Cochlodinium polykrikoides. Algae. 2014;29(4):311-9.

35. Guo R, Ki J-S. Evaluation and validation of internal control genes for studying gene expression in the dinoflagellate Prorocentrum minimum using real-time PCR. Eur J Protistol. 2011;48(3):199-206.

36. Pfaffl MW. A new mathematical model for relative quantification in real-time RT-PCR. Nucleic Acids Res. 2001;29(9):e45-5.

37. Zhang Y, Zhang S-F, Lin L, Wang D-Z. Comparative transcriptome analysis of a toxin-producing dinoflagellate Alexandrium catenella and its non-toxic mutant. Mar Drugs. 2014;12(11):5698-718.

38. Meyer JM, Rödelsperger C, Eichholz K, Tillmann U, Cembella A, McGaughran A, et al. Transcriptomic characterisation and genomic glimps into the toxigenic dinoflagellate Azadinium spinosum, with emphasis on polykeitde synthase genes. BMC Genomics. 2015;16(1):27.

39. De Coninck DI, Janssen CR, De Schamphelaere KA. An investigation of the inter-clonal variation of the interactive effects of cadmium and Microcystis aeruginosa on the reproductive performance of Daphnia magna. Aquat Toxicol. 2013;140:425-31.

40. World Health Organization. Guidelines for drinking-water quality: recommendations, vol. 1. Geneva; WHO, 2004.

41. Baumgarten S, Bayer T, Aranda M, Liew YJ, Carr A, Micklem G, Voolstra CR. Integrating microRNA and mRNA expression profiling in Symbiodinium microadriaticum, a dinoflagellate symbiont of reef-building corals. BMC Genomics. 2013;14:704

42. Ponmani T, Guo R, Ki J-S. Analysis of the genomic DNA of the harmful dinoflagellate Prorocentrum minimum: a brief survey focused on the noncoding RNA gene sequences. J Applied Phycology. 2015: doi:10.1007/ s10811-10015-10570-10810

43. Lee D-H, Mittag M, Sczekan S, Morse D, Hastings J. Molecular cloning and genomic organization of a gene for luciferin-binding protein from the dinoflagellate Gonyaulax polyedra. J Biol Chem. 1993;268(12):8842-50.

44. Li L, Hastings JW. The structure and organization of the luciferase gene in the photosynthetic dinoflagellate Gonyaulax polyedra. Plant Mol Biol. 1998; 36(2):275-84.

45. Okamoto OK, Robertson DL, Fagan TF, Hastings JW, Colepicolo P. Different regulatory mechanisms modulate the expression of a dinoflagellate ironsuperoxide dismutase. J Biol Chem. 2001;276(23):19989-93.

46. Morse D, Milos PM, Roux E, Hastings JW. Circadian regulation of bioluminescence in Gonyaulax involves translational control. Proc Natl Acad Sci. 1989;86(1):172-6.

47. Weake VM, Workman JL. Inducible gene expression: diverse regulatory mechanisms. Nat Rev Genet. 2010;11(6):426-37.

48. Sormani R, Masclaux-Daubresse C, Daniele-Vedele F, Chardon F. Transcriptional regulation of ribosome components are determined by stress according to cellular compartments in Arabidopsis thaliana. PLoS ONE. 2011;6(12), e28070.

49. Liu X-D, Xie L, Wei Y, Zhou X, Jia B, Liu J, et al. Abiotic stress resistance, a novel moonlighting function of ribosomal protein RPL44 in the halophilic fungus Aspergillus glaucus. Appl Environ Microbiol. 2014;80(14):4294-300.

50. Contreras-Porcia L, Dennett G, González A, Vergara E, Medina C, Correa JA, et al. Identification of copper-induced genes in the marine alga Ulva compressa (Chlorophyta). Marine Biotechnol. 2011;13(3):544-56.

51. MacQuarrie KL, Fong AP, Morse RH, Tapscott SJ. Genome-wide transcription factor binding: beyond direct target regulation. Trends Genet. 2011;27(4):141-8.

52. Hahn S, Young ET. Transcriptional regulation in Saccharomyces cerevisiae: transcription factor regulation and function, mechanisms of initiation, and roles of activators and coactivators. Genetics. 2011;189(3):705-36.

53. Hook SE, Osborn HL, Gissi F, Moncuquet P, Twine NA, Wilkins MR, et al. RNA-Seq analysis of the toxicant-induced transcriptome of the marine diatom, Ceratoneis closterium. Mar Genomics. 2014;16:45-53.
54. Sudo E, Itouga M, Yoshida-Hatanaka K, Ono Y, Sakakibara H. Gene expression and sensitivity in response to copper stress in rice leaves. J Exp Bot. 2008;59(12):3465-74

55. Xiong B, Zhang W, Chen L, Lin K-F, Guo M-J, Wang W-L, et al. Effects of Pb (II) exposure on Chlorella protothecoides and Chlorella vulgaris growth, malondialdehyde, and photosynthesis-related gene transcription. Environ Toxicol. 2014;29(11):1346-54.

56. Xu J, Lan H, Fang H, Huang X, Zhang H, Huang J. Quantitative Proteomic Analysis of the Rice (Oryza sativa L.) Salt Response. PLoS ONE. 2015;10(3):e0120978.

57. Zhu J, Patzoldt WL, Radwan O, Tranel PJ, Clough SJ. Effects of photosystemII-interfering herbicides atrazine and bentazon on the soybean transcriptome. The Plant Genome. 2009;2(2):191-205.

58. Wu S, Zhang H, Yu X, Qiu L. Toxicological responses of Chlorella vulgaris to dichloromethane and dichloroethane. Environ Eng Sci. 2014;31(1):9-17.

59. Gonzalez-Mendoza D, Escoboza-Garcia F, Santamria JM, Zapata-Perez O. Copper stress on photosynthesis of black mangle (Avicennia germinans). An Acad Bras Cienc. 2013;85(2):665-70.

60. Küpper H, Šetlík I, Spiller M, Küpper FC, Prášil O. Heavy metal-induced inhibition of photosynthesis: targets of in vivo heavy metal chlorophyll formation. J Phycol. 2002;38(3):429-41.

61. Blot N, Mella-Flores D, Six C, Le Corguillé G, Boutte C, Peyrat A, et al. Light history influences the response of the marine cyanobacterium Synechococcus sp. WH7803 to oxidative stress. Plant Physiol. 2011;156(4):1934-54.

62. Braun HP, Binder S, Brennicke A, Eubel H, Fernie AR, Finkemeier I, et al. The life of plant mitochondrial complex I. Mitochondrion. 2014;2014(19):295-313.

63. Jacoby RP, Li L, Huang S, Pong Lee C, Millar AH, Taylor NL. Mitochondrial Composition, Function and Stress Response in Plants. J Integr Plant Biol. 2012;54(11):887-906

64. Garcia L, Welchen E, Gonzalez DH. Mitochondria and copper homeostasis in plants. Mitochondrion. 2014;19:269-74.

65. Guo R, Ebenezer V, Ki J-S. PmMGST3, a novel microsomal glutathione Stransferase gene in the dinoflagellate Prorocentrum minimum, is a potential biomarker of oxidative stress. Gene. 2014;546(2):378-85.

66. Asada K. Production and scavenging of reactive oxygen species in chloroplasts and their functions. Plant Physiol. 2006;141(2):391-6.

67. Ponmani T, Guo R, Suh YS, Ki J-S. Molecular characterisation and expression analysis of a novel calreticulin (CRT) gene in the dinoflagellate Prorocentrum minimum. Mol Biol Rep. 2015;42(3):681-8.

68. Poljsak B, Šuput D, Milisav I. Achieving the balance between ROS and antioxidants: when to use the synthetic antioxidants. Oxid Med Cell Longev. 2013;2013.

69. Patwari P, Lee RT. Thioredoxins, mitochondria, and hypertension. Am J Pathol. 2007;170(3):805-8.

70. Ahsan MK, Lekli I, Ray D, Yodoi J, Das DK. Redox regulation of cell survival by the thioredoxin superfamily: an implication of redox gene therapy in the heart. Antioxid Redox Signal. 2009;11(11):2741-58.

71. Poole LB, Hall A, Nelson KJ. Overview of peroxiredoxins in oxidant defense and redox regulation. Current Protocols in Toxicology 2011:Unit7.9.

72. Herve C, de Franco P, Groisillier A, Tonon T, Boyen C. New members of the glutathione transferase family discovered in red and brown algae. Biochem J. 2008;412:535-44.

73. de Franco P-O, Rousvoal S, Tonon T, Boyen C. Whole genome survey of the glutathione transferase family in the brown algal model Ectocarpus siliculosus. Mar Genomics. 2008;1(3):135-48.

74. Nordberg J, Arner ES. Reactive oxygen species, antioxidants, and the mammalian thioredoxin system. Free Radic Biol Med. 2001;31(11):1287-312.

75. Poynton RA, Hampton MB. Peroxiredoxins as biomarkers of oxidative stress. Biochimica et Biophysica Acta (BBA)-General Subjects. 2014;1840(2):906-12.

76. Dietz K-J. Peroxiredoxins in plants and cyanobacteria. Antioxid Redox Signal. 2011;15(4):1129-59.

77. Ritter A, Dittami SM, Goulitquer S, Correa JA, Boyen C, Potin P, et al. Transcriptomic and metabolomic analysis of copper stress acclimation in Ectocarpus siliculosus highlights signaling and tolerance mechanisms in brown algae. BMC Plant Biol. 2014;14(1):116.

78. Lovazzano C, Serrano C, Correa JA, Contreras-Porcia L. Comparative analysis of peroxiredoxin activation in the brown macroalgae Scytosiphon gracilis and Lessonia nigrescens (Phaeophyceae) under copper stress. Physiol Plant. 2013;149(3):378-88.

79. Sordet C, Contreras-Porcia L, Lovazzano C, Goulitquer S, Andrade S, Potin P, et al. Physiological plasticity of Dictyota kunthii (Phaeophyceae) to copper excess. Aquat Toxicol. 2014;150:220-8. 